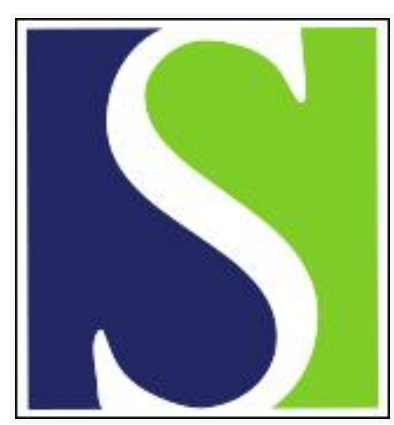

Scand J Work Environ Health 2019;45(4):423-424

https://doi.org/10.5271/sjweh.3836

Published online: 05 Jun 2019, Issue date: 01 Jul 2019

Binding occupational exposure limits for carcinogens in the EU - necessary but not sufficient to reduce risk

by Cherrie JW

Affiliation: Institute of Biological Chemistry, Biophysics and Bioengineering, Heriot Watt University, Edinburgh, UK. john.cherrie@iom-world.org

Refers to the following text of the Journal: 2019;45(3):213-214

The following article refers to this text: 2020;46(1):110-112

Key terms: cancer; carcinogen; exposure; exposure limit; exposure limit value; letter; occupational cancer; occupational exposure; occupational exposure; occupational exposure limit; work-related cancer

This article in PubMed: www.ncbi.nlm.nih.gov/pubmed/31256196

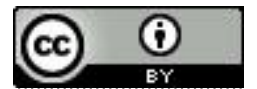




\section{Binding occupational exposure limits for carcinogens in the EU-necessary but not sufficient to reduce risk}

Johanson \& Tinnerberg (1) discuss the role of binding occupational exposure limit values (BOELV) in the European Union and whether these are "good" or "bad". They highlight that the main legislative tool used by the European Commission to achieve reductions in health risks from carcinogen exposure at work is the BOELV. In the past, these limits have often been set at levels linked to high risk. For example, the authors cite data for respirable crystalline silica where exposure to $0.1 \mathrm{mg} / \mathrm{m}^{3}$ over a working career of 45 -years would result in $>1 \%$ of those exposed dying from work-related lung cancer, non-malignant respiratory disease, or kidney disease. The editorial speculates on possible reasons why some limits "are outrageously high and breach the fundamental rights of safe and healthy working conditions"; perhaps regulators suspect the scientists are overplaying the risks or maybe they assume employers will not just comply with the law but try to minimize exposures as far below the limit as possible. However-although not considered by the authors-perhaps the most likely reason is that historically levels have been high and suddenly achieving a stringent standard of control is judged impracticable. Breach of a BOELV is a criminal offence and, in my opinion, no legislator should enact laws that might criminalize a large proportion of those affected.

In preparation for the revision of the EU Carcinogens and Mutagens Directive (2004/37/EC), my research team and I evaluated the health and socioeconomic impact of possible new BOELV for 25 hazardous substances as part of the so-called SHEcan project (2). We estimated that around $26 \%$ of workers in Europe were exposed to respirable crystalline silica $>0.1 \mathrm{mg} / \mathrm{m}^{3}$ and almost half were exposed $>0.05 \mathrm{mg} / \mathrm{m}^{3}$. We estimated that - with no intervention-440 000 Europeans would die from lung cancer caused by occupational silica exposure between 2010 and 2069. Introducing a BOELV of $0.1 \mathrm{mg} / \mathrm{m}^{3}$ could save almost 100000 premature deaths, although ironically over the same period a limit of 0.05 $\mathrm{mg} / \mathrm{m}^{3}$ would only save around a further 10000 lives because the long latency for cancer means that much of the risky exposure has occurred prior to the introduction of the BOELV. The real benefit of low limits is for young workers who will potentially have a large part of their working life in much better conditions than their predecessors.
The SHEcan project also predicted that around 230000 people will die from lung cancer from workplace exposure to diesel engine exhaust particulate. Here we have no BOELV and little prospect of a limit that will save many lives. The limit evaluated in our project was $0.1 \mathrm{mg} / \mathrm{m}^{3}$ respirable elemental carbon (REC), but this had no likely health impact. A more realistic healthbased limit would be around $0.00001 \mathrm{mg} / \mathrm{m}^{3}$, resulting in an estimated four extra deaths from lung cancer per 100000 exposed for 40 years, as has been proposed by the Dutch Health Council (3). However, this limit is clearly impracticable because it is below the levels typically found in ambient air in most European city streets.

The real problem with BOELV is with the concept of a legally enforceable limit that clearly must be set so that compliance is possible. We need a change in the workplace protection paradigm and a move towards a process of continuous improvement rather than just meeting a minimum standard - what the Japanese call kaizen (4). This kind of approach would require employers to demonstrate ongoing efforts to reduce exposures in the workplace by applying good practice and ideally to monitor and regularly report on the exposure levels in the workplace. The best way of achieving this kind of approach might be to set a BOELV that was designed to protect workers from the worst conditions in industry and a target OELV that employers should strive to attain. This is somewhat like the approach that has been adopted in Germany for workplace carcinogens where they propose a "tolerable limit" corresponding to a concentration of a substance with a risk of 4 per 1000 and an "acceptable limit" with risk of 4 per 100000 (5). For example, the German Committee on Hazardous Substances has published technical rules for hazardous substances relating to activities involving carcinogenic metals and their compounds (6). These rules set challenging binding limits for industry to achieve and even more challenging targets to strive towards (table 1). As yet the utility of this approach is unproven and further research is needed.

However, a more pragmatic approach to setting BOELV may be required because some substances currently present a risk greater than the a "tolerable" value, ie, 4 per 100 000. For example, for diesel exhaust particulate the BOELV might need to be around $0.05 \mathrm{mg} / \mathrm{m}^{3}$ 
Table 1. Long-term limit values for three carcinogenic metals and compounds $\left(\mathrm{mg} / \mathrm{m}^{3}\right)$. [R=respirable; I=inhalable]. Values in the table taken from the GESTIS International Limit Values database (https://limitvalue.ifa.dguv.de)

\begin{tabular}{lrrr}
\hline Agent (aerosol size fraction) & $\begin{array}{c}\text { German } \\
\text { "Acceptable" }\end{array}$ & \multicolumn{2}{c}{ German } \\
"Tolerable" & Sweden \\
\hline Arsenic compounds (inhalable fraction) & 0.00083 & 0.0083 & 0.01 \\
Cadmium and inorganic cadmium compounds (inhalable fraction) & $0.00016(\mathrm{R})$ & 0.001 & 0.005 (R) \\
Cobalt and cobalt compounds (respirable fraction) & 0.0005 & 0.005 & 0.025 \\
\hline
\end{tabular}

as REC to allow employers to comply, based on typical measurements in industry (7), but this limit would do little to reduce the predicted death toll from occupational exposure to diesel exhaust particulate.

BOELV are neither good nor bad, but rather they are a necessary part of ensuring a safe workplace. However, on their own they are not sufficient to achieve the kind of progress we would like to see. We really need to consider legislation and a health and safety system that promotes a culture of continuous improvement of workplace conditions.

\section{References}

1. Johanson G, Tinnerberg H. Binding occupational exposure limits for carcinogens in the EU - good or bad? Scand J Work Environ Health. 2019 Apr 10;45(3):213-4. https://doi. org/10.5271/sjweh.3825

2. Cherrie JW, Hutchings S, Gorman Ng M, Mistry R, Corden C, Lamb J, et al. Prioritising action on occupational carcinogens in Europe: a socioeconomic and health impact assessment. Br J Cancer. 2017 Jul 11;117(2):274-81. https://doi.org/10.1038/ bjc. 2017.161
3. DECOS. Diesel Engine Exhaust. Report No.: 2019/02. The Hague: Health Council of the Netherlands; 2019.

4. Cherrie JW. Kaizen. Annals of Work Exposures and Health. 2017 May 1;61(4):398-400. https://doi.org/10.1093/annweh/ wxx015

5. BAuA. The risk-based concept for carcinogenic substances developed by the Committee for Hazardous Substances [Internet]. Dortmund: BAuA; 2013. Available from: www. baua.de/dok/3581564

6. Committee on Hazardous Substances (AGS). Technical Rules for Hazardous Substances. Activities involving carcinogenic metals and their compounds. TRGS 5612017. Dortmund: BAuA; 2017. Available from: https://www.baua.de/EN/ Service/Legislative-texts-and-technical-rules/Rules/TRGS/ pdf/TRGS-561.pdf

7. Pronk A, Coble J, Stewart PA. Occupational exposure to diesel engine exhaust: a literature review. J Expos Sci Environ Epidemiol. 2009 Jul;19(5):443-57. https://doi.org/10.1038/ jes.2009.21

John W Cherrie, PhD a, b

a Institute of Biological Chemistry, Biophysics and Bioengineering, Heriot Watt University, Edinburgh, UK.

b Institute of Occupational Medicine, Edinburgh, UK

[email: john.cherrie@iom-world.org] 